\title{
Lymph node ratio is a prognostic factor for non-small cell lung cancer
}

\author{
Guangyuan Sun ${ }^{1}$, Lei Xue ${ }^{1}$, Mingdong Wang ${ }^{1}$ and Xuewei Zhao ${ }^{1}$ \\ ${ }^{1}$ Department of Thoracic and Cardiovascular Surgery, Changzheng Hospital, the Second Military Medical University, Shanghai, \\ China \\ Correspondence to: Xuewei Zhao, email: xueweizhao123@126.com \\ Keywords: non-small cell lung cancer, lymph node ratio, association, meta-analysis \\ Received: July 09, $2015 \quad$ Accepted: August 22, 2015 \\ Published: September 15, 2015
}

This is an open-access article distributed under the terms of the Creative Commons Attribution License, which permits unrestricted use, distribution, and reproduction in any medium, provided the original author and source are credited.

\section{ABSTRACT}

The lymph node ratio (LNR) is defined as the number of pathologically positive LNs divided by the number of LNs examined. Some studies reported that high LNR was significantly associated with poor survival of non-small cell lung cancer (NSCLC). However, other studies could not confirm this result. PubMed, Embase, and the Cochrane Register of Controlled Trials were searched for relevant studies published up to July 2015. Primary outcome was the relationship between LNR and diseasespecific survival (DSS) and overall survival (OS). Twelve studies with 25138 NSCLC patients were included in this meta-analysis. Higher LNR was significantly associated with decreased OS $(H R=1.93 ; 95 \%$ CI $1.64-2.28 ; P<0.00001)$ and DSS $(H R=$ $1.82 ; 95 \%$ CI $1.55-2.14 ; P<0.00001)$. In the subgroup analysis, N1 stage NSCLC patients with higher LNR also showed decreased OS (HR = 1.60; 95\% CI 1.25 - 2.28; $P=0.0002)$ and DSS (HR = 1.82; 95\% CI $1.55-2.21 ; P<0.0001)$. This meta-analysis indicated that LNR was an independent predictor of survival in patients with NSCLC.

\section{INTRODUCTION}

The long-term survival of non-small cell lung cancer (NSCLC) after surgical resection remains low due to the complex biological characteristics and high recurrence and metastasis [1]. Five-year survival rates for surgically resectable NSCLC are still unsatisfactory and range from $19 \%$ for stage IIIA to $63 \%$ for stage IA [2]. Therefore, the identification of predictive and/or prognostic markers is important to stratify patients with resected NSCLC and select high-risk patients who should receive aggressive adjuvant chemotherapy.

The lymph node ratio (LNR), defined as the number of pathologically positive LNs divided by the number of LNs examined, has been reported as a useful prognostic metric. LNR incorporates both the number of pathologically positive LNs and the number of LNs examined. Some studies reported that high LNR was significantly associated with poor survival. However, other studies could not confirm this result [3-14]. Thus, the result is still controversial. We performed this metaanalysis to assess the relationship between LNR and prognosis of NSCLC.

\section{RESULTS}

Eligible studies

The process of identifying studies is shown in Figure 1. A total of 18 publications were identified in the initial search. Based on screening of titles or abstracts, 3 records were excluded. Full text articles were retrieved only for 15 publications and assessed for eligibility. Of these 15 publications, 3 publications were excluded. Finally, 12 studies were included in this meta-analysis.

Twelve studies with 25138 NSCLC patients were included in this meta-analysis. These studies were conducted ranged from 2011 to 2015 . The median followup duration ranged from 1.8 to 17 years. The quality score ranged from 6 to 9 . The characteristics of included studies were showed in Table 1. 
Table 1: Characteristics of the studies included in this meta-analysis

\begin{tabular}{|c|c|c|c|c|c|c|c|c|c|c|}
\hline First author & Year & Age (years) & T stage & $\mathrm{N}$ stage & $\begin{array}{l}\text { Case } \\
\text { number (n) }\end{array}$ & $\begin{array}{l}\text { Follow-up } \\
\text { duration (years) }\end{array}$ & $\begin{array}{l}\text { Disease-specific } \\
\text { survival reported }\end{array}$ & $\begin{array}{l}\text { Overall } \\
\text { survival reported }\end{array}$ & Adjust & Scores \\
\hline Jonnalagadda & 2011 & $<65$ & T1-T3 & $\mathrm{N} 1$ & 4004 & 15 & Yes & Yes & age, sex, race, histology, tumor site and status, type of surgery, and receipt of radiation therapy & 8 \\
\hline Wisnivesky & 2011 & $>65$ & $\mathrm{~T} 1-\mathrm{T} 3$ & $\mathrm{~N} 1$ & 1682 & 15 & Yes & Yes & $\begin{array}{l}\text { age, sex, race/ethnicity, marital status, estimated income, comorbidities, histology, tumour status } \\
\text { and location, type of surgery and use of chemotherapy or radiation therapy. }\end{array}$ & 8 \\
\hline Matsuguma & 2012 & NA & $\mathrm{Tl}-\mathrm{T} 3$ & $\mathrm{~N} 0-\mathrm{N} 2$ & 651 & 17 & No & Yes & $\begin{array}{l}\text { age, gender, histology, pathological T status, surgical type, postoperative chemotherapy, and } \\
\text { postoperative radiotherapy. }\end{array}$ & 7 \\
\hline Nwogu & 2012 & $\mathrm{NA}$ & $\mathrm{NA}$ & $\mathrm{N} 0-\mathrm{N} 2$ & 5012 & 4 & Yes & Yes & age, race, sex, tumor size, and histologic grade of the tumor & 8 \\
\hline Wang & 2011 & $31-78$ & $\mathrm{~T} 1-\mathrm{T} 3$ & $\mathrm{~N} 1-\mathrm{N} 2$ & 301 & 10 & Yes & Yes & Histologic type, stage, smoking, No. of involved nodes & 7 \\
\hline $\mathrm{Li}$ & 2013 & 64 & $\mathrm{Tl}-\mathrm{T} 3$ & $\mathrm{NA}$ & 206 & 5 & No & Yes & $\begin{array}{l}\text { different nodal involvement pattern, the ratio of the number of positive LNs to the total number } \\
\text { of LNs removed, number of LNs involved, patient age, sex, history of smoking, pathologic type, } \\
\text { type of resection, VPI, lymph vascular invasion, and tumor size }\end{array}$ & 6 \\
\hline Qiu & 2013 & 59 & $\mathrm{~T} 1-\mathrm{T} 3$ & $\mathrm{~N} 0-\mathrm{N} 2$ & 480 & 3 & Yes & Yes & $\begin{array}{l}\text { age, sex, smoking status, location of tumor, histology, pathology T stage, pathology N stage, } \\
\text { surgical procedure, chemotherapy, metastatic lymph node }\end{array}$ & 6 \\
\hline Taylor & 2013 & $\mathrm{NA}$ & $\mathrm{NA}$ & $\mathrm{N} 1-\mathrm{N} 2$ & 1143 & 3.7 & Yes & No & $\begin{array}{l}\text { age, sex, use of preoperative radiation, use of preoperative chemotherapy, preoperative ECOG } \\
\text { status, pathologic tumor stage, } \mathrm{N} \text { stage, } \mathrm{T} \text { stage, total lymph nodes removed }\end{array}$ & 7 \\
\hline Urban & 2013 & 66 & T1-T4 & $\mathrm{N} 1-\mathrm{N} 2$ & 11324 & 1.8 & No & Yes & age, sex, race, grade, histology, laterality, surgery, pathology $\mathrm{T}$ stage, pathology N stage & 8 \\
\hline Hsieh & 2014 & 60.2 & T0-T3 & $\mathrm{N} 2$ & 108 & 2.4 & Yes & Yes & T stage, Angiolymphatic invasion, Perineural invasion, operation & 6 \\
\hline Wu & 2014 & $34-83$ & $\mathrm{Tl}-\mathrm{T} 3$ & $\mathrm{NI}$ & 75 & 5.5 & Yes & Yes & Sex, smoking, adjuvant therapy, angiolymphatic invasion, histology & 6 \\
\hline Renaud & 2015 & 58.5 & T1-T4 & $\mathrm{N} 0-\mathrm{N} 2$ & 152 & 2.7 & No & Yes & $\begin{array}{l}\text { Adjuvant treatment, Extracapsular spread, pathology } \mathrm{T} \text { stage, pathology } \mathrm{N} \text { stage, Type of } \\
\text { surgery, Charlson comorbidity index }\end{array}$ & 7 \\
\hline
\end{tabular}

NA, not available.

Table 2: Results of the meta-analysis.

\begin{tabular}{|c|c|c|c|c|c|c|c|c|}
\hline & \multirow{2}{*}{$\begin{array}{l}\text { No. of } \\
\text { studies }\end{array}$} & \multicolumn{3}{|c|}{ Test of association } & \multirow[b]{2}{*}{ Model } & \multicolumn{3}{|c|}{ Heterogeneity } \\
\hline & & $\mathrm{HR}(95 \% \mathrm{CI})$ & $Z$ & $P$ Value & & $\chi^{2}$ & $P$ Value & $I^{2}(\%)$ \\
\hline Overall survival & 11 & $1.93(1.64-2.28)$ & 7.83 & $<0.00001$ & $\mathrm{R}$ & 16.22 & 0.09 & 38.0 \\
\hline $\mathrm{N} 1$ & 3 & $1.60(1.25-2.05)$ & 3.73 & 0.0002 & $\mathrm{R}$ & 1.45 & 0.49 & 0.0 \\
\hline Large scale $(n>1000)$ & 4 & $1.60(1.36-1.88)$ & 5.73 & $<0.00001$ & $\mathrm{R}$ & 3.01 & 0.39 & 0.0 \\
\hline Small scale $(\mathrm{n}<1000)$ & 7 & $2.32(1.91-2.82)$ & 8.55 & $<0.00001$ & $\mathrm{R}$ & 4.76 & 0.57 & 0.0 \\
\hline Disease-specific survival & 8 & $1.82(1.55-2.14)$ & 7.31 & $<0.00001$ & $\mathrm{R}$ & 4.36 & 0.74 & 0.0 \\
\hline $\mathrm{N} 1$ & 3 & $1.70(1.31-2.21)$ & 3.98 & $<0.0001$ & $\mathrm{R}$ & 1.54 & 0.46 & 0.0 \\
\hline Large scale $(n>1000)$ & 4 & $1.75(1.42-2.15)$ & 5.32 & $<0.00001$ & $\mathrm{R}$ & 1.86 & 0.60 & 0.0 \\
\hline Small scale $(n<1000)$ & 4 & $1.93(1.50-2.50)$ & 5.04 & $<0.00001$ & $\mathrm{R}$ & 2.16 & 0.54 & 0.0 \\
\hline
\end{tabular}

$\mathrm{R}$, random-effects model.

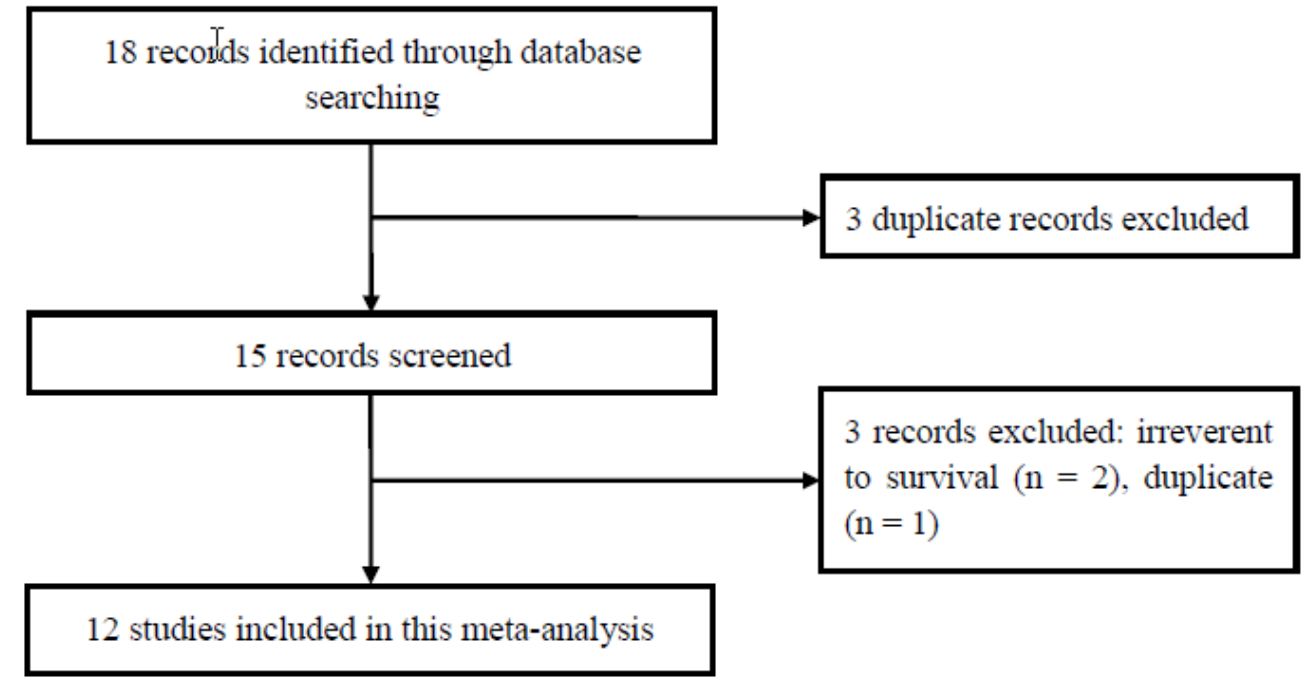

Figure 1: The selection of included studies. 


\section{Quantitative data synthesis}

As shown in Figure 2, higher LNR was significantly associated with decreased OS (HR $=1.93 ; 95 \% \mathrm{CI}$ $1.64-2.28 ; P<0.00001)$. In the subgroup analysis, N1 stage NSCLC patients with higher LNR was also associated with decreased OS (HR $=1.60 ; 95 \%$ CI 1.25 - 2.28; $P=0.0002)$. As shown in Figure 3, higher LNR was significantly associated with decreased DSS (HR = $1.82 ; 95 \%$ CI $1.55-2.14 ; P<0.00001)$. In the subgroup analysis, N1 stage NSCLC patients with higher LNR was also associated with decreased DSS (HR $=1.82 ; 95 \%$ CI $1.55-2.21 ; P<0.0001)$. In the subgroup analysis by sample size, both studies with large scale and small scale showed similar results (Table 2).

Sensitivity analysis did not change the results of this meta-analysis (Figures 4 and 5). The funnel plot and Egger's test were performed for the overall comparison. No obvious visual asymmetry was observed in funnel plots (Figures 6 and 7), and the $P$ values of the Egger's test were greater than 0.05 .

\section{DISCUSSION}

This meta-analysis of 12 observational studies showed that NSCLC patients with higher LNR had worse outcome. NSCLC patients with N1 stage showed similar results.

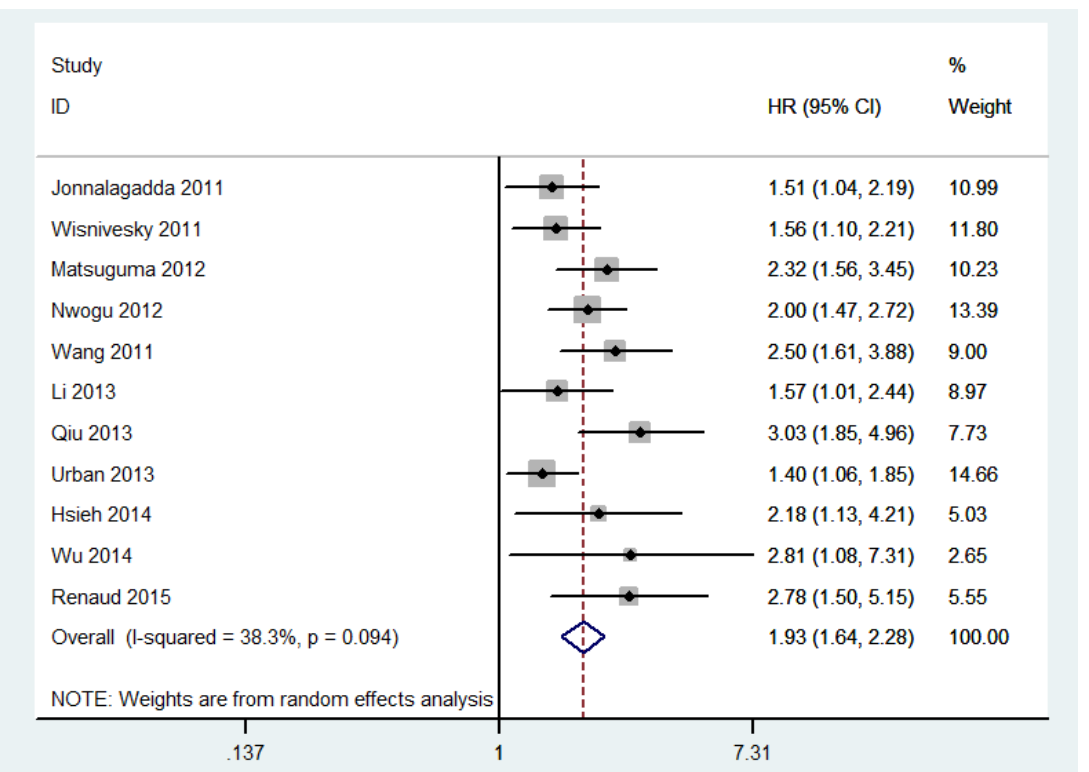

Figure 2: Meta-analysis of the association between LNR and OS.

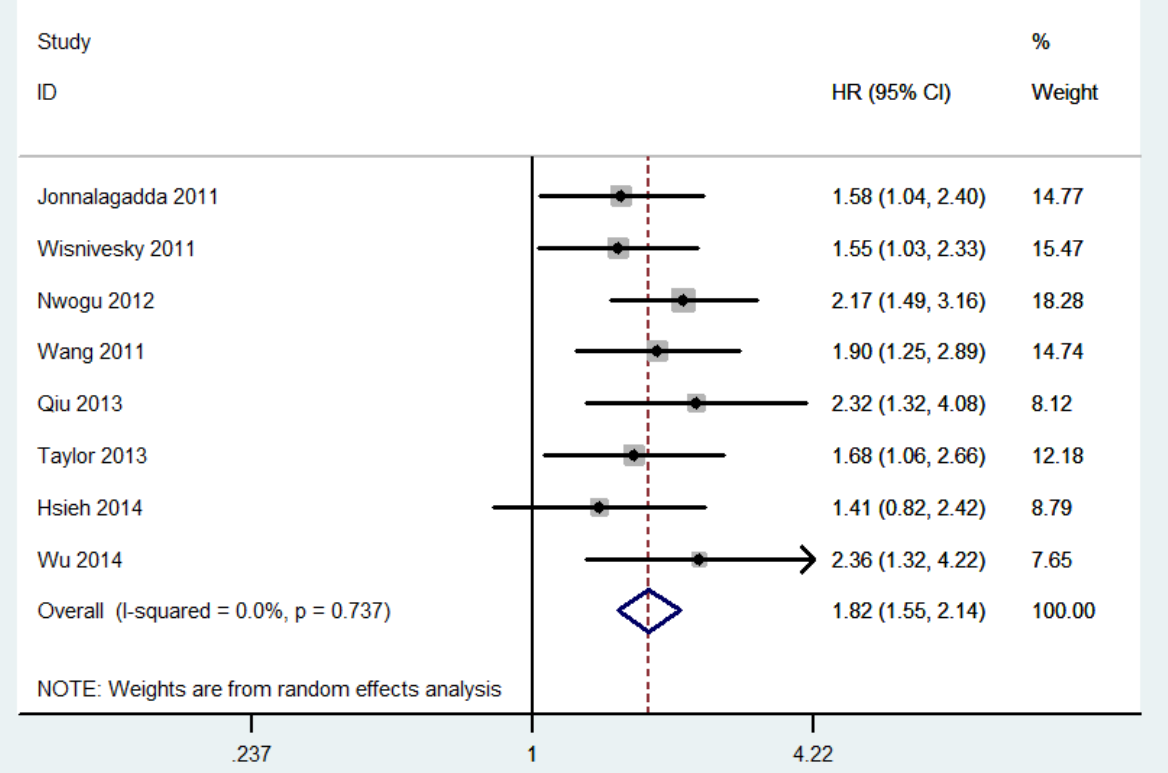

Figure 3: Meta-analysis of the association between LNR and DSS. 


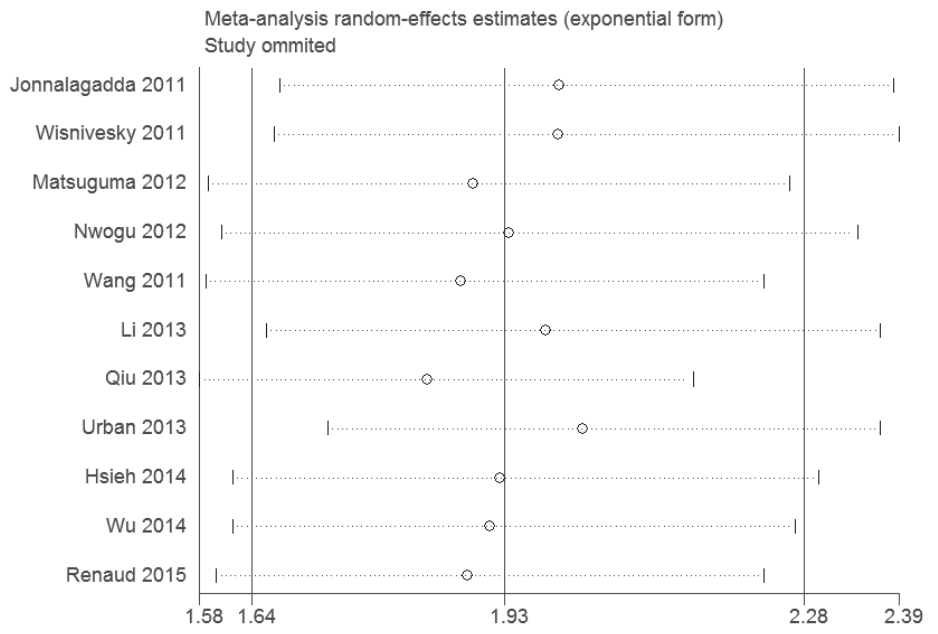

Figure 4: Sensitivity analysis of the association between LNR and OS.

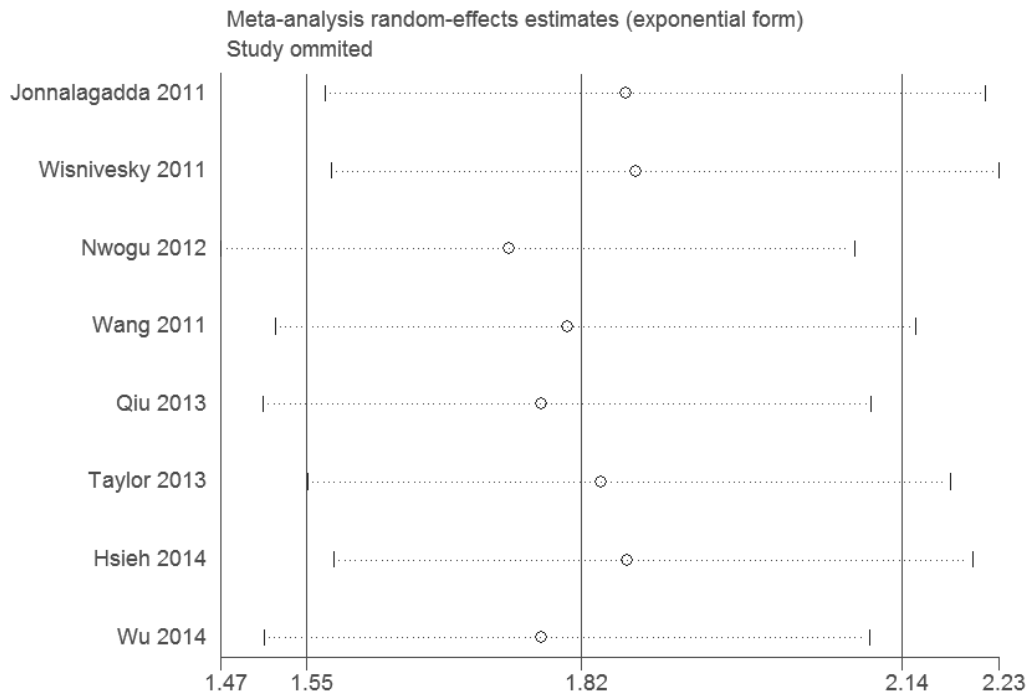

Figure 5: Sensitivity analysis of the association between LNR and DSS.

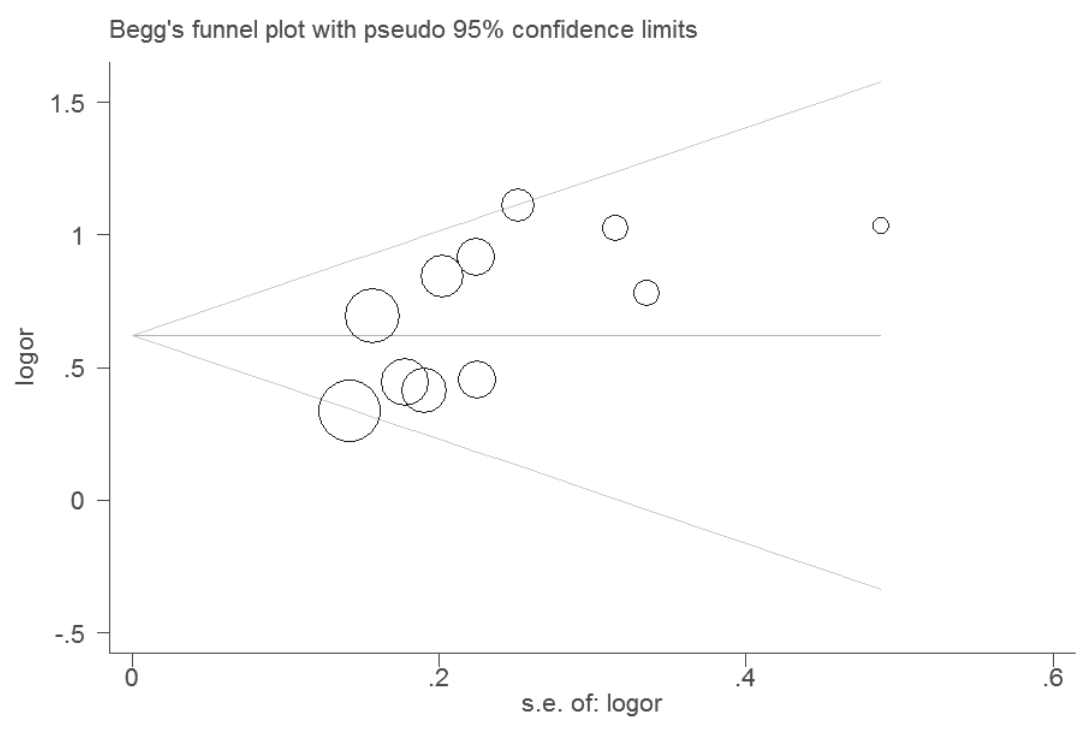

Figure 6: Funnel plot of the association between LNR and OS. 


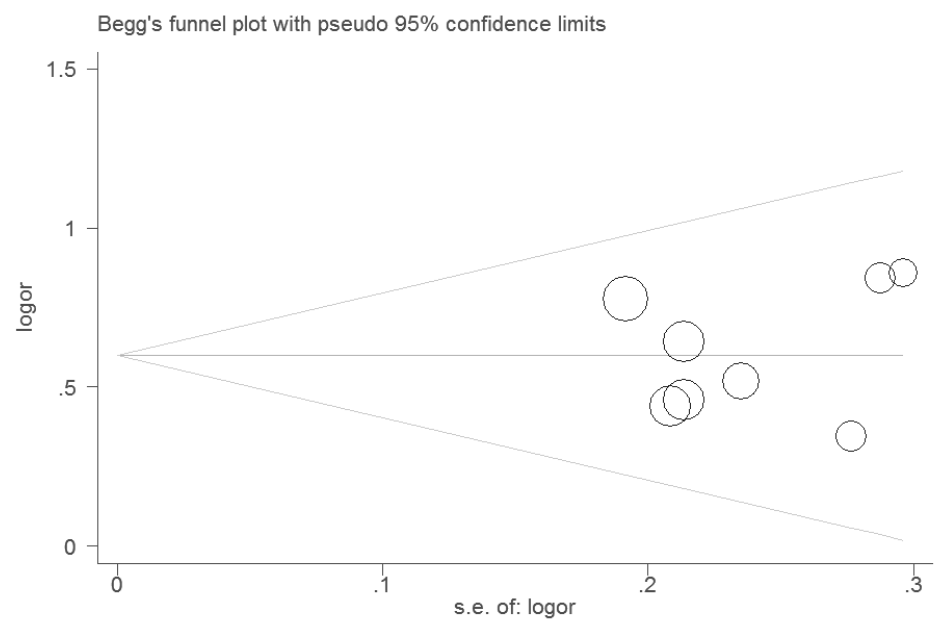

Figure 7: Funnel plot of the association between LNR and DSS.

The studies suggested that LNR could be a prognostic factor in other cancers. For example, Chen et al. showed that a staging system based on LNR may have better prognostic stratification of patients with esophageal squamous cell carcinoma than the current TNM system [15]. Liao et al. indicated that LNR was an important prognostic factor with regard to OS for patients with node-positive breast cancer [16]. Kutlu and colleagues suggested that LNR is an effective tool to predict survival in a western gastric cancer patient population [17]. Zhan and colleagues indicated that LNR was an independent adverse prognostic factor for pancreatic cancer [18]. In addition, Fleming et al. suggested that LNR appears to be a useful tool to identify patients with worse prognosis in node-positive early stage cervical cancer [19].

Recent studies also investigated whether patients with high LNR should receive radiotherapy. Urban et al. indicated that the survival benefit associated with postoperative radiotherapy seemed to be limited to patients with high LNR [11]. However, whether patients with high LNR should receive adjuvant chemotherapy is needed to be investigated in the future.

Our study had some advantages. First, this is the first meta-analysis about LNR and outcome of NSCLC. Second, the statistic power is well enough for this metaanalysis. However, this study also had several limitations. First, all the included studies were observational retrospective investigations. Second, lacking of the original data of the eligible studies limited the evaluation of the effects of LNR on different populations, such as smoker and non-smoker, adenocarcinoma and squamous cell carcinoma. Third, although we performed an extensive review of the main electronic databases, we cannot be sure to have included all relevant studies.

In conclusion, this meta-analysis indicated that LNR was an independent predictor of survival in patients with NSCLC.

\section{MATERIALS AND METHODS}

\section{Publication search}

PubMed, Embase, and the Cochrane Register of Controlled Trials were searched for relevant studies published up to July 2015. The following terms were used: ("NSCLC" or "lung cancer" or "non-small cell lung cancer") and ("lymph node ratio" or "LNR"). The MeSH terms were used: "Lung Neoplasms" or "Carcinoma, NonSmall-Cell Lung". No language restrictions were imposed. References from relevant articles, including review papers, were also reviewed.

\section{Selection and exclusion criteria}

Studies were included in the meta-analysis if they fulfilled the following inclusion criteria: 1) study design: cohort studies; 2) population: patients with NSCLC; 3) primary outcome: the relationship between LNR and disease-specific survival (DSS) and overall survival (OS). Abstract, case reports, review articles, experimental studies and commentary articles were excluded. Eighteen studies were searched from PubMed, Embase, and the Cochrane Register of Controlled Trials. However, four duplicate studies and two studies without of survival were excluded. At last, twelve studies were selected for this meta-analysis.

\section{Data extraction}

Two investigators reviewed and extracted information independently from selected publications in accordance with the above mentioned inclusion and exclusion criteria. Any conflicts over study/data inclusion were settled by a discussion between the investigators. 
The following items were extracted from each study if available: first author, year of publication, age, T stage, $\mathrm{N}$ stage, sample size, follow-up years, and covariates.

\section{Qualitative assessment}

Two authors completed the quality assessment independently. The Newcastle-Ottawa Scale (NOS) was used to evaluate the methodological quality, which scored studies by the selection of the study groups, the comparability of the groups, and the ascertainment of the outcome of interest. We considered a study awarded 0-3, 4-6, or 7-9 as a low-, moderate-, or high-quality study, respectively.

\section{Statistical analysis}

We estimated the hazard ratio (HR) with $95 \%$ confidence interval (CI) for primary outcome. The multivariable-adjusted HRs with 95\% CIs were pooled in this analysis. Heterogeneity of the combined studies was assessed with Cochran's Q-statistic test and $\mathrm{I}^{2}$ test. The P value of Cochran's Q-statistic of below 0.05 , was considered statistically significant heterogeneity. The $\mathrm{I}^{2}$ test provides a measure of the degree of heterogeneity in the results. Typically, values of $0 \sim 25 \%$ are considered to represent no heterogeneity, $25 \sim 50 \%$ to modest heterogeneity, $50 \sim 75 \%$ to large heterogeneity and $75 \sim 100 \%$ to extreme heterogeneity. A random effects model was applied. Subgroup analysis and sensitivity analysis were performed. Sensitivity analyses were conducted to assess the strength of our findings by excluding one study at a time. Publication bias was investigated by Egger's test. All statistical analyses were performed with STATA 11.0 software.

\section{CONFLICTS OF INTEREST}

The authors declare that they have no conflicts of interest.

\section{REFERENCES}

1. Jemal A, Bray F, Center MM, Ferlay J, Ward E, Forman D. Global cancer statistics. CA Cancer J Clin. 2011;61:69-90.

2. Osarogiagbon RU, Allen JW, Farooq A, Berry A, O'Brien T. Pathologic lymph node staging practice and stagepredicted survival after resection of lung cancer. Ann Thorac Surg. 2011;91:1486-92.

3. Wisnivesky JP, Arciniega J, Mhango G, Mandeli J, Halm EA. Lymph node ratio as a prognostic factor in elderly patients with pathological N1 non-small cell lung cancer. Thorax. 2011;66:287-93.

4. Jonnalagadda S, Arcinega J, Smith C, Wisnivesky JP.
Validation of the lymph node ratio as a prognostic factor in patients with N1 nonsmall cell lung cancer. Cancer. 2011;117:4724-31.

5. Matsuguma H, Oki I, Nakahara R, Ohata N, Igarashi S, Mori K, Endo S, Yokoi K. Proposal of new nodal classifications for non-small-cell lung cancer based on the number and ratio of metastatic lymph nodes. Eur J Cardiothorac Surg. 2012;41:19-24.

6. Nwogu CE, Groman A, Fahey D, Yendamuri S, Dexter E, Demmy TL, Miller A, Reid M. Number of lymph nodes and metastatic lymph node ratio are associated with survival in lung cancer. Ann Thorac Surg. 2012;93:1614-9.

7. Wang CL, Li Y, Yue DS, Zhang LM, Zhang ZF, Sun BS. Value of the metastatic lymph node ratio for predicting the prognosis of non-small-cell lung cancer patients. World J Surg. 2012;36:455-62.

8. Li ZM, Ding ZP, Luo QQ, Wu CX, Liao ML, Zhen Y, Chen ZW, Lu S. Prognostic significance of the extent of lymph node involvement in stage II-N1 non-small cell lung cancer. Chest. 2013;144:1253-60.

9. Qiu C, Dong W, Su B, Liu Q, Du J. The prognostic value of ratio-based lymph node staging in resected non-small-cell lung cancer. J Thorac Oncol. 2013;8:429-35.

10. Taylor MD, Lapar DJ, Thomas CJ, Persinger M, Stelow EB, Kozower BD, Lau CL, Jones DR. Lymph node ratio predicts recurrence and survival after R0 resection for nonsmall cell lung cancer. Ann Thorac Surg. 2013;96:1163-70.

11. Urban D, Bar J, Solomon B, Ball D. Lymph node ratio may predict the benefit of postoperative radiotherapy in nonsmall-cell lung cancer. J Thorac Oncol. 2013;8:940-6.

12. Hsieh CP, Fu JY, Liu YH, Yang CT, Hsieh MJ, Tsai $\mathrm{YH}, \mathrm{Wu} \mathrm{YC}, \mathrm{Wu} \mathrm{CY}$. Prognostic factors in resectable pathological N2 disease of non-small cell lung cancer. Biomed J. 2014. doi: 10.4103/2319-4170.145765. [Epub ahead of print]

13. Wu CF, Wu CY, Fu JY, Wang CW, Liu YH, Hsieh MJ, Wu YC. Prognostic value of metastatic N1 lymph node ratio and angiolymphatic invasion in patients with pathologic stage IIA non-small cell lung cancer. Medicine (Baltimore). 2014;93:e102.

14. Renaud S, Falcoz PE, Olland A, Reeb J, Santelmo N, Massard G. Mediastinal downstaging after induction treatment is not a significant prognostic factor to select patients who would benefit from surgery: the clinical value of the lymph node ratio. Interact Cardiovasc Thorac Surg. 2015;20:222-7.

15. Chen SB, Weng HR, Wang G, Zou XF, Liu DT, Chen YP, Zhang H. Lymph node ratio-based staging system for esophageal squamous cell carcinoma. World J Gastroenterol. 2015;21:7514-21.

16. Liao GS, Chou YC, Golshan M, Hsu HM, Hong ZJ, Yu JC, Zhu JH. Prognostic value of the lymph node ratio in breast cancer subtypes. Am J Surg. 2015;210:749-54.

17. Kutlu OC, Watchell M, Dissanaike S. Metastatic lymph 
node ratio successfully predicts prognosis in western gastric cancer patients. Surg Oncol. 2015;24:84-88.

18. Zhan HX, Xu JW, Wang L, Zhang GY, Hu SY. Lymph node ratio is an independent prognostic factor for patients after resection of pancreatic cancer. World J Surg Oncol. 2015;13:105.

19. Fleming ND, Frumovitz M, Schmeler KM, dos Reis R, Munsell MF, Eifel PJ, Soliman PT, Nick AM, Westin SN, Ramirez PT. Significance of lymph node ratio in defining risk category in node-positive early stage cervical cancer. Gynecol Oncol. 2015;136:48-53. 